\title{
Universidade moderna: dos interesses do Estado-nação às conveniências do mercado*
}

\author{
ZULEIDE SIMAS DA SILVEIRA \\ Universidade Federal Fluminense, \\ Niterói, RJ, Brasil \\ LUCÍDIO BIANCHETTI
} Universidade Federal de Santa Catarina, Florianópolis, SC, Brasil

\section{RESUMO}

Este texto analisa as transformações pelas quais vem passando a universidade brasileira em relação à configuração institucional, ao financiamento, à gestão e à produção do conhecimento. Primeiramente, dá destaque aos modelos de universidade humboldtiano, napoleônico e norte-americano, de modo que se possa captar o desenvolvimento dessas concepções, sua convergência e materialização na universidade modernizada. Em seguida, desvela que, no decurso dos processos de internacionalização da economia, a ideia de universidade passa a alinhar-se, historicamente, aos desígnios do desenvolvimento econômico por mediação da política científico-tecnológica, sob a orientação de organismos supranacionais e intelectuais orgânicos do capital. Por fim, aponta para a contrarreforma universitária como triplo processo: integração subordinada da educação à política de ciência, tecnologia e inovação; diversificação e hierarquização institucional segundo a oferta e duração dos cursos; e empresariamento da educação.

\section{PALAVRAS-CHAVE}

universidade; contrarreforma universitária; mercantilização da educação.

* Uma versão deste texto serviu de base para nossa intervenção na Sessão Especial n. 12, "Políticas públicas de educação superior" (GT-5, GT-9 e GT-11), no decorrer da 36a Reunião Anual da Associação Nacional de Pós-Graduação e Pesquisa em Educação (ANPEd), realizada em Goiânia entre 29 de setembro e 2 de outubro de 2013. 


\title{
MODERN UNIVERSITY: FROM THE INTERESTS OF THE NATION-STATE TO MARKET ADVANTAGES
}

\begin{abstract}
This paper examines the transformations of the Brazilian university in relationship to the institutional configuration, forms of financing, management and production of knowledge. First, it emphasizes the Humboldtian, Napoleonic and North American university models in order to capture the development of these concepts and their convergence and materialization in the modern university. After that, it reveals that through a processes of economic internationalization, the idea of the university came to gradually and historically align itself to the designs of economic development through the of scientific and technological policy, under the guidance of supranational organisms and organic intellectuals of capital. Finally, it points to the university counter-reform as well as a triple process that includes: the subordinated integration of education with science, technology and innovation policy; institutional diversification and hierarchization according to the supply and length of the courses; and entrepreneurship education.
\end{abstract}

KEYWORDS

university; university counter-reform; mercantilization of education.

\section{UNIVERSIDAD MODERNA: DE LOS INTERESES DEL ESTADO-NACIÓN A LAS CONVENIENCIAS DEL MERCADO}

\section{RESUMEN}

Este artículo analiza las transformaciones que viene sufriendo la universidad brasileña en relación a su marco institucional, al financiamiento, a la gestión y a la producción de conocimiento. En primer lugar destaca los modelos de universidad -humboldtiano, napoleónico y norteamericano- a fin de que se pueda captar el desarrollo de dichas concepciones, su convergencia y materialización en la universidad modernizada. Luego, desvela que a lo largo de los procesos de internacionalización de la economía, la idea de universidad va aliñándose, históricamente, a los designios del desarrollo económico, por medio de la política científica-tecnológica, bajo la orientación de los organismos supranacionales e intelectuales orgánicos del capital. Por fin, indica la contrarreforma universitaria como triple proceso: integración subordinada de la educación a la política para la ciencia, la tecnología y la innovación; diversificación y jerarquización institucional según la oferta y la duración de los cursos y empresarización de la educación.

PALABRAS CLAVE

universidad; contrarreforma universitaria; mercatilización de la educación. 


\section{INTRODUÇÃO}

Desde as origens do Estado moderno, a concepção de universidade é atravessada pelo caráter instrumental, no sentido de responder às demandas e aos tempos econômico, industrial, tecnológico e urbano da ordem capitalista. Entretanto, ao longo do desenvolvimento histórico dessa concepção, alguns de seus aspectos vão se modificando no que diz respeito às formas de financiamento e de gestão, à configuração institucional e, especificamente, de produção do conhecimento.

A partir do final da década de 1970 e início de 1980, com a subida ao poder das forças políticas ultraconservadoras na Inglaterra, nos Estados Unidos e na Alemanha - representadas, respectivamente, por Margareth Thatcher, em 1979, Ronald Reagan, em 1980, e Helmut Kohl, em 1982 -, marcadamente neoliberais, ${ }^{1}$ as políticas contrarreformistas ${ }^{2}$ no campo da educação superior passam a alterar as regras tradicionais de gestão e financiamento universitário. Separam as universidades de ensino daquelas de pesquisa, promovem a hierarquização do ensino e de instituições com base em processos de avaliação padronizados, além de intervir não só na liberdade acadêmica em nome da "eficiência" e da "produtividade"(Bianchetti, 2008; Bianchetti; Quartiero, 2010), mas também na autonomia universitária, que passa a ser entendida como atributo de um movimento de aproximação ao setor empresarial.

A contrarreforma universitária, em curso, traz em seu bojo preocupações marcantes com as competências e habilidades que interessam ao mercado competitivo, de tal forma que a universidade passe a responder às dinâmicas dos processos de internacionalização da economia, ${ }^{3}$ em níveis mundial, regional e nacional.

1 Note-se que, durante o processo que torna hegemônico o neoliberalismo, a social-democracia, de revisão em revisão, vai se amoldando à onda neoliberal, transformando os governos social-democratas em decididos executores da política neoliberal (Anderson, 1995; Fiori, 2007). Neoliberalismo e social-democracia não são forças antagônicas, ao contrário, formam o par perfeito na manutenção do sistema capitalista (Silveira, 2011). Fica clara, então, a convergência de François Mitterrand (1916-1996), presidente da França entre 1981 e 1995, às iniciativas dos seus congêneres neoliberais, em especial no recuo do Welfare State.

2 Para Gramsci (2002), o processo de contrarreforma, embora apresentado como refor$m a$, é um movimento conservador, de caráter regressivo. $\mathrm{O}$ período de hegemonia das políticas neoliberais, em curso, pode ser compreendido como um processo de contrarreforma, tendo em vista suas reformas, a exemplo da reforma universitária, não serem mais que engodo e instrumento de destruição das conquistas dos trabalhadores, trazendo em seu bojo a precarização e flexibilização do trabalho, a formação aligeirada e fragmentada, a desorganização da classe trabalhadora e o enfraquecimento dos sindicatos combativos.

3 Chesnais (1996), ao elaborar a categoria mundialização do capital, evidencia um duplo fenômeno (globalização e neoliberalismo), que associa a expansão e o domínio do capital financeiro sobre o capital produtivo a certo tipo de política e ideologia. Assim, a noção de internacionalização inclui não apenas o comércio exterior e os fluxos internacionais de capital, mas também a entrada e saída de tecnologias (seja incorporada aos equipamentos, seja transmitida e adquirida de forma intangível), os movimentos internacionais de pessoal qualificado e os fluxos transfronteiriços de informação e dados. 
Nesse período de introdução das políticas neoliberais, as críticas aos modelos de universidade humboldtiana e napoleônica parecem retomar as orientações do Relatório Robbins ${ }^{4}$ e do Relatório Atcon, ${ }^{5}$ ambos produzidos no início da década de 1960, afinando-se a dois pensamentos complementares: (i) de Jean-François Lyotard (1924-1998), que, sob a encomenda do Conselho das Universidades de Québec, produziu o relatório $A$ condição pós-moderna; ${ }^{6}$ (ii) de Bill Readings (1960-1994), professor da Universidade de Montreal, autor de Universidade sem cultura? e $A$ universidade em ruinas.

Passados mais de trinta anos, as ideias de Lyotard e de Readings, assumidamente pós-modernos, materializam-se de forma gradativa no modelo anglo-saxão modernizado de universidade. Esse é o presente histórico, marcado por tensões em torno da função social da universidade, cujo discurso pós-moderno ancora-se na visão de classe burguesa em determinada conjuntura histórico-social do capitalismo, o neoliberalismo tornado hegemônico a partir dos anos 1990.

O tempo da pesquisa, neste trabalho, remonta às concepções de universidade nas origens do Estado moderno, estendendo-se até o período de introdução e realização das políticas neoliberais no Brasil, período este demarcado, no plano econômico, pelos programas de modernização tecnológica e inserção competitiva do país na economia mundial tendo por base a política de ciência, tecnologia e inovação, e, no plano educacional, pelo conjunto de indicações e de legislação levados a cabo nos mandatos de Fernando Henrique Cardoso (1995-2003), Luiz Inácio Lula da Silva (2003-2011) e continuado no Governo Dilma Rousseff.

O texto está estruturado da seguinte forma: primeiro dá destaque aos modelos de universidade humboldtiano, napoleônico e norte-americano, de modo que capte o desenvolvimento dessas concepções, sua convergência e materialização na universidade modernizada. Em seguida, evidencia as orientações de intelectuais orgânicos do capital e de organismos supranacionais, bem como os instrumentos legais que vêm norteando as modificações pelas quais vem passando a universidade

4 O Report Robbins - the report of the Committee on Higher Education, presidido por Lord Robbins (1898-1984), foi elaborado entre os anos de 1961 e 1963. Disponível em: $<$ http://www.educationengland.org.uk/documents/robbins/index.html>. Acesso em: maio 2011.

5 Esse relatório, elaborado sob a coordenação de Rudoph P. Atcon, consultor da Organização das Nações Unidas para a Educação, a Ciência e a Cultura (UNESCO) e da Agência dos Estados Unidos para o Desenvolvimento Internacional (USAID), foi publicado originalmente no ano de 1961 e encontra-se disponível em <http:// pt.scribd.com/doc/36270991/Rudolph-Atcon-La-Universidad-a-v-libro>. Acesso em: fev. 2010. O consultor Rudolph Atcon, grego de nascimento, naturalizado cidadão norte-americano e de formação intelectual alemã, chegou à América Latina e ao Caribe em fins da década de 1950. No Brasil, assessorou Anísio Teixeira no processo de implantação da Coordenação de Aperfeiçoamento de Pessoal de Nível Superior (CAPES), trabalhando como subdiretor do Programa Universitário entre 1953 e 1956. Além do Brasil, Atcon atuou na reforma universitária de países como Chile, Colômbia, Venezuela, Honduras e, ainda, do Caribe (Fávero, 1991, p. 20).

6 Publicado pela primeira vez no Brasil em 1986, o texto recebeu o título de O pós-moderno até a sua quarta edição. 
brasileira, coerentemente com os processos de internacionalização da economia e os desígnios do desenvolvimento econômico por mediação da política científico-tecnológica. Por fim, aponta para os processos de privatização, comodificação e mercantilização da educação e seus desdobramentos no plano de desenvolvimento institucional, na padronização de currículos e instrumentos de avaliação sob a ação do marco regulatório do Setor Educacional do Mercado Comum do Sul - MERCOSUL (SEM), por mediação do Estado.

\section{IDEIA DE UNIVERSIDADE: ALGUNS ANTECEDENTES DA SITUAÇÃO ATUAL}

A economia do século XIX foi formada principalmente sob a influência da revolução industrial britânica, sendo sua política e ideologia engendradas fundamentalmente pela Revolução Francesa. A dupla revolução burguesa estimulou a educação científica e técnica, do que a ciência passa a se beneficiar expressivamente (Hobsbawm, 2012).

É nesse contexto de ordem intelectual, com vistas ao progresso, que surgem várias obras sobre a educação, em geral, e a universidade, em particular, como $O$ conflito das faculdades (1798), de Immanuel Kant (1724-1804); Por uma universidade orgânica de Erlangene (1805) e Plano dedutivo de uma instituição de ensino superior a ser edificada em Berlim, que esteja estreitamente associada a uma Academia de Ciências (1807), ambas de Johann Gottlieb Fichte (1762-1814); Pensamentos de circunstância sobre a universidade segundo a concep̧̧ão alemã (1808), de Friedrich Schleiermacher (1768-1834); e Sobre a organização interna e externa das instituições científicas superiores em Berlim (1810), de Wilhelm von Humboldt (1767-1835).

A obra deste último é sucinta e inacabada, mas consistente como sistematização teórico-filosófica sobre a universidade, sua organização e gestão, bem como sobre a necessidade de cooperação entre professores e entre estes e o corpo discente; a unidade entre pesquisa e ensino; a complementaridade da educação básica com a superior; a liberdade de produção da ciência "pura" e infinita; e também a relação estreita, porém autônoma, entre Estado e universidade.

Partidário da visão de que o Estado educador é aquele Estado absoluto, sepultado entre os escombros da Revolução, e de que caberia ao Estado liberal apenas garantir as regras do livre jogo individual para o desenvolvimento pacífico das forças produtivas (Barros, 1986, p. 73-74), Humboldt planeja a organização universitária alemã de modo que concilia liberdade de ensino com a intervenção estatal. Encontra-se aí a tensão inerente à necessidade de compatibilizar a expansão indefinida da liberdade de pensar com o ordenamento de caráter político, jurídico e escolar.

Essa concepção idealista, liberal ou "interna" desenvolve-se com base na concepção de universidade que se organiza de acordo com normas próprias. Nesse sentido, caberia ao Estado garantir o desempenho da missão da universidade, a seleção dos cientistas e, ao mesmo tempo, proteger a liberdade acadêmica de indesejados interesses conflituosos entre classes e frações de classe, igreja e categorias profissionais, estabelecendo, para tanto, um controle dos planos curriculares, de modo que não interfira na liberdade individual de ensinar e de aprender. 
No que diz respeito à relação externa destas [instituições científicas superiores] com o Estado, basta que ele se limite a garantir a riqueza da força espiritual, isto é, seu poder e diversidade. O Estado promove tal riqueza na medida em que seleciona os cientistas e, ao mesmo tempo, assegura liberdade para seu trabalho. A autonomia fica ameaçada não apenas pelo Estado, mas também pelas próprias instituições quando, ao assumirem determinada orientação, impedem a emergência de qualquer outra. (Humboldt, 2003, p. 87)

Para Humboldt (idem, p. 83-84), o "Estado necessita [de um lado], respeitar a lógica interna da ciência", posto que "os princípios mais importantes" da organização das "instituições científicas superiores" encontram-se na sua autonomia e liberdade quanto à produção da ciência e pesquisa, em geral, e da vida intelectual, em particular, sem prejuízos à atividade científica; de outro, deve beneficiar-se do desenvolvimento da ciência, que, voltada para o bom "andamento dos negócios do Estado", facilitará o acesso de "elites burocráticas" (Gomes, 1994) a sua atividade estatal. Nesse sentido, a universidade moderna torna-se um instrumento destinado à construção e reforço do Estado.

Encontra-se aí o germe da universidade voltada para o desenvolvimento, ${ }^{7}$ cabendo à educação cumprir papel preponderante no processo de mediar a construção e modernização do Estado. Nesse sentido:

A incorporação da Universidade no âmbito da coordenação do Estado foi concomitante com o desenvolvimento do Estado-Nação na Europa, quer como símbolo e como repositório da identidade nacional, quer como instrumento para conservação da cultura nacional e, através da unificação cultural como a manifestação da exigência de um país a um lugar entre as nações - o equivalente cultural das preocupações actuais, mais restritas, com a competitividade econômica [...] E acrescente-se, a construção do Estado-Nação caminhou lado a lado com a incorporação da academia nas fileiras do serviço de Estado, cumprindo-se, assim, a implícita obrigação de servir a comunidade nacional. (Neave apud Amaral; Magalhães, 2000)

Em síntese, o modelo humboldtiano assume a universidade como uma instituição que goza de autonomia relativa na produção do conhecimento, em relação estreita com os interesses do Estado, tendo a ciência como a força unificadora de que o Estado necessita para legitimar o projeto de nacionalidade. A formação, demarcada por uma concepção idealista, liberal e acadêmica, põe a pesquisa científica no centro das relações universitárias, enfatizando a indissociabilidade entre ensino, pesquisa e formação geral, humanista e científica, com foco na totalidade e universalidade do

7 Sobre a "universidade para o desenvolvimento", Florestan Fernandes afirma que toda universidade contribui para o processo de humanização e, portanto, para o desenvolvimento da sociedade. Entretanto, cabe investigar para que tipo de desenvolvimento ela vem sendo adaptada, direcionada e induzida (Fernandes, 1975, p. 114-123; 2004, p. 273-316).). 
saber. Essa seria a forma de fazer a ciência "pura", que tem como princípio a busca infinita da verdade e do conhecimento.

Entretanto, um aspecto merece destaque: a possibilidade, em Humboldt, da existência de diferentes instituiçôes superiores científicas, ou do que hoje constitui o denominado sistema de ensino superior. Isto é, a concepção humboldtiana de universidade já traz em seu bojo a "divisão das instituiçôes cientificas superiores e os diversos tipos de instituição resultantes desta divisão" (Humboldt, 2003, p. 91-99, grifos do original). De um lado, a universidade, estatal, incumbida do ensino, da produção e divulgação da ciência pura e do controle de institutos isolados a ela vinculados por mediação do Estado; de outro, a academia, não estatal e de interesse privado, encarregada, ao mesmo tempo, da produção da ciência pura e das ciências da observação e da experimentação, além dos Privatdozenten, também instituições de direito privado, voltadas exclusivamente para as questões práticas e, portanto, de ciência aplicada.

No que diz respeito ao modelo napoleônico de universidade - que substitui a antiga universidade (voltada para a formação teológico-jurista e humanista, organização corporativista em seu sentido medieval e autônoma ante o poder público) por um sistema centralizado na Universidade Imperial, constituído de academias (os, hoje, campi), que se estendem aos Países Baixos e à Itália -, ele também é fruto do desenvolvimento da técnica, da ciência e da tecnologia da Revolução Industrial e, sobretudo, da República Jacobina de 1793, cujas escolas superiores passaram a constituir o estrato superior do sistema educacional francês, formando quadros para a classe dirigente, enquanto ao restante da população era destinada a formação de nível primário e secundário.

Em conformidade com o renascimento científico, inaugurado por Isaac Newton (1642-1727) no século XVII, em que a razão combina-se de forma harmoniosa com a observação empírica e sistemática, a ciência moderna firma-se em relação à antiga cultura escolástica, estabelecendo uma analogia entre o universo newtoniano e o ideal de justiça e riqueza social a ser conquistado pela liberdade individual e racionalidade que a revolução industrial burguesa estava a exigir.

Nesse contexto, a ciência oficial - que se pretendia neutra, técnica e universal, conferindo ao processo de conhecimento o caráter de objetividade e matematicidade, fundamentada em uma filosofia não mais especulativa - torna-se utilitária, de modo que coloca o domínio da técnica a serviço da classe burguesa em consolidação. Se o modelo humboldtiano regride ao pensamento de Kant, que, ao distinguir o uso privado da razão do uso público, busca conciliar a autonomia do saber com a obediência às determinações do Estado, o modelo francês, de sua parte, articula-se ao pensamento de René Descartes (1596-1650), Denis Diderot (1713-1784) ${ }^{8}$ e

8 Segundo Piozzi (2004, p. 659-660), o Plano de uma universidade, redigido por Diderot, expõe detalhadamente a proposta de instrução superior, aberta a todos aqueles que tivessem concluído a escola primária. O Plano, finalizado em 1775, ainda que afirme a universidade como uma escola "aberta indistintamente a todos os filhos de uma nação e onde os mestres estipendiados pelo Estado os iniciam ao conhecimento elementar de todas as ciências", traz no bojo de sua proposta a hierarquização entre elites pensantes e homens comuns. Sua "insistência sobre a esterilidade do curriculum, que reúne em si 
Marie Jean Antoine Nicolas de Caritat, o Marquês de Condorcet (1743-1794), ${ }^{9}$ enfatizando o caráter instrumental da universidade como instituição própria do saber objetivo e provedora de forças profissionais que, em termos teóricos e práticos, teria como meta a ordem e o progresso, por meio do domínio e da instrumentalização da natureza.

Como já se destacou, essa concepção de universidade encontra-se em Descartes, para quem a universalidade do saber deve desembocar na universalidade do progresso. A transformação dos modos de produção e a transformação da ciência condicionam-se mutuamente, bem como a universidade, desde sua estrutura, sua razão epistêmica, e até seu sentido social. Desse modo, a universidade, sede do saber funcional e promotora do progresso, não se deve limitar à busca de verdades, mas manter-se a serviço da criação de conhecimentos e técnicas com vistas à produção (Goergen, s.d.).

É dentro desse ideário que se coloca a reforma napoleônica de educação como instrumento, ao mesmo tempo, de coerção, controle social e construção de hegemonia em torno da ideologia do Estado, comandada por Napoleão Bonaparte (1769-1821). ${ }^{10}$ A lei de criação da universidade napoleônica subsidiou a introdução de uma administração centralizada de todo ensino, por meio de um conselho superior com atribuições administrativas, disciplinares e pedagógicas (Rodriguéz, 2004, p. 26), com a finalidade de difundir uma doutrina comum, tendo como mediação o corpo docente. As questões de ordem sociopolíticas e socioeconômicas seriam atribuídas e resolvidas pela educação, pois que tudo dela depende e seu centro irradiador é a universidade. Nessa direção:

a herança da escolástica medieval e o cultivo das letras clássicas, originário do humanismo renascentista, sugere que a proposta de modernização deve privilegiar os saberes que seriam mais adequados aos campos profissionais florescentes com a mecanização do trabalho e o extraordinário incremento da produção e da troca, em curso na época”, destinados, portanto, à maioria capacitada para o exercício das artes mecânicas e dos negócios comuns; enquanto à minoria de homens, "nascidos" para meditar e tornar-se "poetas", "oradores" ou "filósofos", estaria destinado o conhecimento "primitivo" das ciências da natureza e da moral.

9 Segundo Piozzi (2004), depois da tomada da Bastilha, em 14 de julho de 1789, Condorcet, um dos líderes ideológicos da revolução, matemático e filósofo, encaminhou à Assembleia Nacional um projeto de organização geral da instrução pública como modelo da escola do Estado-nação: única, pública, gratuita, laica e universal. Para Condorcet, a instrução não é apenas obrigação do Estado educador, mas também condição básica para seu funcionamento. Sobre esse aspecto, ver também Condorcet (2008).

10 "Em 2 de dezembro de 1804, Napoleão Bonaparte inicia o regime absolutista, que duraria dez anos, introduzindo um novo sistema que reforçou na cultura luso-brasileira a velha herança pombalina do despotismo ilustrado. Se é certo que Portugal antecedeu com sua aritmética política ao sistema napoleônico de poder unipessoal, alicerçado na ciência, o Imperador dos Franceses consolidou o modelo de ditadura generosa que seria adotado por Henri-Claude de Saint Simon e pelo seu discípulo Auguste Comte, os quais deram início ao arquétipo de ditadura cientifica, que polarizou o debate antimonarquista no Brasil do século XIX, tendo passado a inspirar diretamente nossas instituições republicanas" (Rodriguéz, 2004, p. 2, grifos do original). 
De todas as instituições, a mais importante é a instrução pública. Dela tudo depende, o presente e o passado. É necessário que a moral e as ideias políticas da geração que se educa não dependam das novidades do dia ou das circunstâncias do momento. É preciso, antes de tudo, chegar à unidade, e que uma geração toda inteira possa ser lançada no mesmo molde. Os homens diferem bastante pelas suas inclinações, pelos seus caracteres e por tudo isso que a educação não deve ou pode reformar. (Napoleão apud Boaventura, 1986, p. 32)

O modelo napoleônico não se apoia em um pensamento filosófico, ele reflete tão somente, em determinado contexto, uma concepção educacional fundamentada nas necessidades práticas da classe dominante, sendo um dos exemplos mais antigos de instrumentalização da universidade pelo Estado, exercida por mediação da legislação, controle financeiro e de nomeações em todo território nacional, com vistas à modernização da sociedade, à construção de uma identidade nacional e à (con)formação da classe trabalhadora.

Não é a esmo que a filosofia cientifica de Saint-Simon (1760-1825) e Auguste Comte (1798-1857) constituiu um esforço intelectual acerca do desenvolvimento da sociedade, particularmente no período da Revolução Francesa e da monarquia napoleônica, no qual os descobrimentos e as invenções da ciência e tecnologia, que desempenhavam papel preponderante na expansão capitalista, fariam o homem caminhar para uma fase em que a organização social e política seria resultado das luzes e da razão.

Quanto ao modelo norte-americano de universidade, desde a década de 1960, particularmente no Brasil do período de refomas educacionais do governo civil-militar, busca-se torná-lo um paradigma universal e universalizante a ser adotado acriticamente.

Cabe ressaltar que os Estados Unidos são um país em que a sociedade burguesa não se desenvolveu sobre as bases do regime feudal, como resultado de um movimento secular, mas, sim, com origem em si mesma, isto é, seu ponto de partida encontra-se subordinado à sociedade burguesa, à sua produção, à aplicação das forças produtivas então existentes no imenso território natural (Marx, 2009). A luta de classes desenvolveu-se na e por meio da sociedade burguesa, na sua relação com o interno e com o externo (a decadente sociedade medieval europeia), baseada nos ideais liberais que se materializam nas declarações de direitos e de independência: a igualdade natural dos indivíduos e sua autonomia em relação ao Estado, o direito à propriedade privada e o gozo da liberdade, entendido como meio de obter e possuir a propriedade e a felicidade.

Assim sendo, "Lehrfreibeit (liberdade de ensinar) e Lernfreibeit (liberdade de aprender) tornam-se as duas forças, que definidas no modelo humboldtiano da Alemanha em suas livres origens, encontram na América seu clima, seu estilo, seu apoio, até agora incontestes" (Teixeira, 1964, p. 32; 1968, p. 41). Tendo a universidade como centro de progresso (Boaventura, 1986, p. 29) e de desenvolvimento econômico da sociedade, o movimento em torno da criação da universidade surge em resposta à industrialização nascente, que nos Estados Unidos não se circunscreve apenas à indústria urbana, mas também à agricultura (Teixeira, 1964). 
Nesse sentido, a concepção americana de universidade surge como resultado de certa tensão entre os modelos humboldtiano e napoleônico, rompendo com a tradição original de formadora, única e exclusiva, de elite. Busca reunir em seu seio as potenciais forças do progresso da sociedade, ao mesmo tempo em que se apresenta como instituição democrática a serviço do interesse geral da nação. Tal concepção, segundo Teixeira $(1964,1968)$ compreende a universidade como aquela que, além do gentleman, do padre, do advogado e do médico, formados nos colleges públicos, iria devotar-se à pesquisa tecnológica e econômica e à investigação em todos os aspectos políticos e sociais, que vinha sendo desenvolvida na Johns Hopkins University, ${ }^{11}$ além de formar quadros de nível intermediário e superior nos land-grant colleges, que visavam ao treinamento de jovens para a agricultura $\mathrm{e}$ para as denominadas artes mecânicas.

Sintetizando, o modelo norte-americano põe ênfase no progresso, fazendo a aspiração dos indivíduos da sociedade convergir para o saber que interessa ao desenvolvimento econômico, buscando, desse modo, associar estritamente os aspectos ideais (ensino e pesquisa) e utilitário (serviço à comunidade ${ }^{12}$ ao funcionamento da sociedade, aspectos estes contemplados, ontem e hoje, em uma multiplicidade de cursos de graduação e pós-graduação de longa e curta duração, oferecidos por diferentes instituições.

\section{A CRISE DA UNIVERSIDADE}

Ao longo do século XX e início do XXI, a universidade, em nível internacional, passa por mudanças significativas no concernente à sua concepção. No Brasil, a organização acadêmico-pedagógica da universidade transita entre os modelos humboldtiano (adotado originalmente na Universidade de São Paulo), napoleônico (legitimado na Universidade do Brasil, do Rio de Janeiro) ${ }^{13}$ e norte-americano (posto

11 Instituição privada, fundada em 1875, com base no modelo humbodtiano.

12 Encontra-se aí o germe da extensão universitária, inaugurada no Brasil pela reforma universitária executada no governo civil-militar. A extensão universitária constitui-se como atividade inerente à universidade, voltada para a prestação de serviços em aparente perspectiva assistencialista, sendo, na essência, objeto de contenção da entrada da classe trabalhadora no ensino superior. Segundo a Equipe de Assessoria ao Planejamento do Ensino Superior (EAPES) daquele governo, a extensão visaria atender a parcela da sociedade que, não tendo acessado ao ensino superior, se beneficiaria de cursos de curta duração na modalidade de aperfeiçoamento, adaptação ou de atualização (Brasil; Ministério da Educação; EAPES, 1969).

13 Segundo Cunha (1980, p. 268), no modelo paulista predominava a ideologia liberal elitista, legitimada pelo regime político liberal-democrático viabilizado pela formação de elites dela imbuídas; no modelo federal sobressaía a ideologia autoritária, legitimando um regime político autoritário, organizado por elites nela formadas e difusoras dessa mesma ideologia por toda a coletividade. E claro que, apesar das diferenças entre o modelo paulista e o modelo federal, existe, em ambos, a preocupação com a formação de uma consciência nacional que coloque a escola em posição neutra, livre das ideologias, e sob os ditames da pátria e da segurança nacional. Entretanto, no modelo federal essa preocupação conduziu a uma visão mais pragmática de universidade, voltada para 
em prática no governo civil-militar sob os acordos entre o Ministério da Educação [MEC] e a USAID - ${ }^{14}$ acordos MEC-USAID, e, a partir da década de 1990, a configuração da universidade torna-se síntese multiplamente determinada pelas concepções alemã, francesa e norte-americana, ajustando-se ao modelo anglo-saxão modernizado (Silveira, 2011).

É no decurso do processo de internacionalização da economia, a partir do pós-Segunda Guerra Mundial, e, ainda, com o processo de institucionalização da política de ciência e tecnologia (C\&T), a partir da década de 1960, que os modelos humboldtiano e napoleônico passam a ser vistos como responsáveis pelo atraso do setor produtivo e do desenvolvimento econômico do país, o que seria decorrência de uma universidade envelhecida, retrógrada, desinteressante, desatualizada e, ainda, que estaria enfrentando a ausência de estímulo dos docentes mergulhados no marasmo de um ensino escolástico, ultrapassado e desajustado das necessidades do Estado-nação.

$\mathrm{Na}$ realidade concreta, o que se discute é a universidade para o desenvolvimento econômico, visto que o momento estava a exigir economistas; engenheiros de operação, voltados para as questões práticas e imediatas do setor produtivo e de formação aligeirada; engenheiros plenos, voltados para a criatividade, projetos e pesquisa, de formação sólida e científica; além de quadros intermediários, a exemplo dos tecnólogos (Silveira, 2010).

os problemas econômicos, políticos e sociais emergentes, em uma vertente autoritária e centralizadora pelo aparelho estatal. Se, na Universidade de São Paulo (USP), a Faculdade de Filosofia, Ciências e Letras exerce sua atividade como uma "universidade em miniatura" (Fernandes, 1963) e órgão central da universidade em sua totalidade, a Universidade do Brasil tem sua autonomia reduzida, na medida em que é mantida e dirigida diretamente pelo Estado. $\mathrm{O}$ embate político que envolve as universidades, entre interesses da nação e interesses particulares, religiosos, profissionais e corporativos, tem como emblema a extinção da Universidade do Distrito Federal, criada por Anísio Teixeira (1900-1971) em meados da década de 1930. Esse mesmo roteiro repetir-se-á, mais tarde, na década de 1960, em plena ditadura civil-militar, quando a Universidade de Brasília, criada por Anísio Teixeira e Darcy Ribeiro (1922-1997), sofre a intervenção do governo, e também na USP, de cuja interposição autoritária cassa, em 1968, o reitor, Hélio Lourenço de Oliveira (1917-1985), e, entre outros, os professores Florestan Fernandes (1920-1995) e Mário Schenberg (1914-1990).

14 Em 19 de dezembro de 1950 foi assinado o acordo geral entre os governos do Brasil e Estados Unidos "para estabelecer o intercâmbio de conhecimentos técnicos e a cooperação em atividades correlatas" com vistas a contribuir para o desenvolvimento econômico e para a elevação da capacidade produtiva do Brasil. A partir desse acordo geral, foram assinados outros acordos: em maio de 1953, o Acordo sobre Serviços Técnicos Especiais complementa o primeiro; em junho de 1965 é assinado o acordo entre a USAID e o MEC para Cooperação Técnica (Ponto IV), no qual a agência norte-americana se compromete a enviar técnicos ao Brasil, para, junto com os brasileiros, reestruturar o sistema nacional de ensino superior. A partir da assinatura deste último acordo, foram baixadas portarias, elaborados pareceres e assinados novos acordos que complementavam os anteriores, até a nomeação da terceira e última comissão brasileira que integrou a EAPES, cujas recomendações foram assumidas pelo governo federal. 
Nesse contexto, na América Latina, o Relatório Atcon - La universidad latinoamericana: clave para un enfoque conjunto del desarrollo coordinado social, económico y educativo en América Latina - terá influência marcante na reforma universitária do Brasil, do Chile e de Honduras. Ainda na América Latina, o Banco Interamericano de Desenvolvimento (BID) promove a mesa-redonda "Higher Education and Latin American Development", realizada em Assunção, Paraguai, em 1965. No Brasil, as reformas educacionais são vistas como coetâneas às modificações ocorridas no processo de industrialização. Este coloca as necessidades, e aquelas vão sendo modificadas para atendê-lo. Todos os níveis de ensino devem sofrer alterações de modo que atendam às necessidades do desenvolvimento, levando em consideração o tipo de clientela a ser atendida em cada um dos níveis da educação escolar.

Estabelece-se, então, um vínculo linear entre educação e desenvolvimento econômico, explicitado em debates, documentos emanados pelo poder público e por entidades de classe do patronato ou intelectuais orgânicos do capital (Cardoso, 1978; Ciavatta, 2009; Fávero, 2001; Frigotto, 2001; Rodrigues, 1998). Conforme explicitado no Relatório Atcon, as universidades da região latino-americana, já no início da década de 1960, inspiradas, em sua grande maioria, no modelo napoleônico, encontravam-se estruturalmente arcaicas diante do "impulso da independência econômica, da industrialização e da crescente demanda de consumo" (Atcon, 1961, p. 12, tradução nossa).

Desse modo, as modificações estruturais da universidade requerem, no plano sociopolítico, "a transição do ensino de elite para o ensino de massas"; no plano tecnológico, "a transformação de instituições meramente acadêmicas em institutos de ciência pura e aplicada"; e, no plano econômico, "a transformação de torres de marfim em instituições a serviço da comunidade”(idem, p. 22). Ressalte-se que essas recomendações não se desvinculam da concepção que atribui ao ensino superior papel estratégico no desenvolvimento dos sistemas nacionais de C\&T e no processo de formação de recursos humanos altamente qualificados.

Portanto, segundo a concepção veiculada pelo Relatório Atcon, o desenvolvimento econômico da região somente seria possível mediante o planejamento integrado e coordenado da economia e da educação, sendo que dele faz parte a política científica e tecnológica, ainda que não explicitada. Desse modo, a universidade, atuando do topo da sociedade, promoveria uma reforma socioeconômica, possibilitando, assim, à região latino-americana cumprir seu papel na economia mundial, formando recursos humanos qualificados, segundo a divisão internacional do trabalho.

Sempre criticando o financiamento da educação por parte do Estado e, ainda, propugnando o aumento do número de instituições de ensino superior (IES) privadas em detrimento das públicas, Atcon (idem), ao apontar a universidade brasileira como deformada no que diz respeito à administração, à organização didático-pedagógica e ao financiamento, entende a autonomia como a liberdade de a universidade selecionar, contratar e demitir pessoal; auto-organizar-se pedagógica, administrativa e financeiramente, com um custo que lhe permita o máximo de rendimento e menor inversão das disponibilidades financeiras dentro do orçamento anual, o que implica obrigação de procurar outras fontes de financiamento, que não o Estado, para suas atividades de ensino, pesquisa e extensão. 
Na Europa, o Relatório Robbins, aprovado pelo governo britânico no ano de 1963, acaba por influenciar nas modificações que se vinham promovendo em França, Espanha e Alemanha, propondo a criação de um sistema de ensino superior articulado, composto por universidades, escolas, faculdades e institutos isolados ou vinculados à universidade e por instituições de formação profissional tecnológica de nível superior; a expansão do número de matrículas no ensino superior; a autonomia financeira da universidade; o enquadramento de cursos de formação profissional tecnológica de nível médio no ensino superior; a transformação de "faculdades avançadas de tecnologia" em universidades tecnológicas; a expansão de institutos superiores de tecnologia; o aperfeiçoamento da pós-graduação com a criação de instituições especializadas no desenvolvimento da pesquisa científica e tecnológica (Ralha, 1968; Robbins, 1963).

Ainda na Europa, o Colóquio de Caen sobre o Ensino Superior, realizado no ano de 1966, em Caen, França, discute a democratização do acesso; a reforma estrutural da universidade diante do arcaísmo do modelo napoleônico baseado nas faculdades e nas cátedras como unidades autônomas; a associação estreita do ensino à pesquisa (Nunes, 1966, p. 685-686).

Guardadas as especificidades regionais - América Latina e Europa -, tanto o Relatório Atcon quanto o Robbins recomendam a adoção do modelo norte-americano de universidade, no que diz respeito à organização administrativa e pedagógica, à autonomia didática e financeira e à finalidade da universidade. Chega-se mesmo a propor a criação de novas universidades, que, introduzidas para adaptar-se às constantes mutações de seu tempo, fariam descer as antigas universidades de suas torres de marfim.

Desse modo, o modelo anglo-saxão, depois de inspirar o modelo americano, passa, a partir deste, a moderniza-se, constituindo-se, gradativa e historicamente, na nova concepção de universidade - de características específicas e funcionais à "modernização conservadora" (Moore Jr., 2010) -, tornada hegemônica, já em fins do século XX e início do XXI, em países de capitalismo central e periférico. Na União Europeia, a contrarreforma do ensino superior promovida pelo Processo de Bolonha é insígnia do modelo anglo-saxão modernizado. No âmbito do MERCOSUL, uma dinâmica de movimento dialético entre governos nacionais e processo de integração regional abre espaço para que se coloque em prática o referido modelo por mediação do Setor Educacional do MERCOSUL (SEM).

No Brasil, em particular, a nova configuração de universidade materializa-se por meio de instrumentos legais que promovem a contrarreforma a retalho, como a lei n. 10.973, de 2 de dezembro de 2004 (Lei de Inovação Tecnológica), que dispõe sobre incentivos à pesquisa científica e tecnológica $;{ }^{15}$ o Sistema Nacional de

15 A referida Lei de Inovação Tecnológica veio compor o arcabouço do sistema nacional de ciência, tecnologia e inovação, sendo uma das manifestações da hélice tripla (Estado, empresa e universidade), de modo que acelere a privatização da produção do conhecimento por meio de parcerias entre universidade, instituições privadas de C\&T e setor produtivo. 
Avaliação da Educação Superior (SINAES) ${ }^{16}$ criado pela lei n. 10.861, de 14 de abril de 2004; o Programa Universidade para Todos (ProUni), institucionalizado pela lei n. 11.096, de 13 de janeiro de 2005; o Programa de Apoio a Planos de Reestruturação e Expansão das Universidades Federais (REUni), instituído pelo decreto n. 6.096, de 24 de abril de 2007; o decreto n. 7.423, de 31 de dezembro de 2010, que regulamenta as parcerias entre as universidades federais e as fundações de direito privado, viabilizando a captação de recursos privados para financiar as atividades de pesquisa científica e tecnológica; o projeto de lei n. 7.200/2006, que estabelece a reforma universitária por meio de normas gerais da educação superior, regula a educação superior no sistema federal de ensino, altera as leis n. 9.394, de 20 de dezembro de 1996, n. 8.958, de 20 de dezembro de 1994, n. 9.504, de 30 de setembro de 1997, n. 9.532, de 10 de dezembro de 1997, e n. 9.870, de 23 de novembro de 1999. Ao projeto de lei n. 7.200/2006, em tramitação, estão apensados três outros, quais sejam, projeto de lei n.7.322/2006, n. 7.444/2006 e n. 4.055/2008.

\section{UNIVERSIDADE MODERNIZADA E ADAPTADA AO MERCADO: A SITUAÇÃO ATUAL}

Historicamente, a organização administrativa e acadêmico-pedagógica da universidade esteve articulada às dinâmicas do Estado, que, por sua vez, veio sendo moldado aos interesses da classe dominante, em geral, e do capital, em particular. Nesse sentido, ao mesmo tempo em que a burguesia brasileira veio internacionalizando-se, de modo que acompanhasse os movimentos de internacionalização da economia, a educação, em geral, e a educação superior, em particular, vieram, cada vez mais, atrelando-se aos interesses do capital, respondendo àquela dinâmica, por mediação da política de ciência, tecnologia e inovação (Silveira, 2011).

Em outras palavras, diante do fato de ter como encargos históricos transmitir o conhecimento socialmente produzido, pesquisar, produzir conhecimento novo e, mais recentemente, inovador, e, ainda que não seja de interesse da classe dominante, gerar pensamento crítico, a universidade veio sendo chamada, permanentemente, a modernizar-se e amoldar-se aos interesses do capital, formando novos quadros, profissionais e de pesquisadores, com diferentes níveis de formação em trabalho

16 O SINAES, em vigor desde 2004, que possui uma série de instrumentos complementares (autoavaliação, avaliação externa, Exame Nacional de Desempenho de Estudantes ENADE), vincula-se ao Instituto Nacional de Estudos e Pesquisas Educacionais Anísio Teixeira (INEP), sendo, entretanto, coordenado pela Comissão Nacional de Avaliação da Educação Superior (CONAES). Além das atribuições do lado brasileiro, a CONAES integra a Rede de Agências Nacionais de Acreditação do MERCOSUL (RANA), responsável pelo processo de definição das diretrizes do Sistema de Acreditação de Cursos de Graduação do SEM/Educação Superior. Ressalte-se que o projeto de lei n. 4.372/2012, do Executivo, cria o Instituto Nacional de Supervisão e Avaliação da Educação Superior (INSAES), uma autarquia que será vinculada ao MEC e que assumirá a tarefa do INEP nos processos de avaliação, acreditação e supervisão dos cursos de graduação e das instituições federais, privadas e beneficentes de ensino superior no Brasil. 
interdisciplinar, particularmente na área científica e tecnológica, incluída a transferência de conhecimento e de tecnologia ao setor empresarial.

Entretanto, será no contexto de hegemonia do neoliberalismo e a partir da consolidação dos sistemas nacionais de ciência, tecnologia e inovação, em fins da década de 1990 e início do século XXI, que a política educacional passará a responder, sistematicamente, à política científico-tecnológica e de inovação, quando se redefine o papel do conhecimento no quadro de modernização e de desenvolvimento econômico e social do estado brasileiro e do respectivo bloco econômico-regional, o MERCOSUL.

Nesse contexto, a produção do consenso em torno da cooperação universidade-empresa intensifica-se por mediação dos organismos supranacionais (UNESCO; Organização para a Cooperação e Desenvolvimento Econômico - OCDE; Banco Mundial; Comissão Econômica para a América Latina e o Caribe - CEPAL e MERCOSUL), os órgãos do poder público e do setor empresarial. Difunde-se o ideário do arranjo institucional que envolve três elementos fundamentais da hélice tripla, como um contributo indispensável à produção de conhecimento inovador e, por conseguinte, à modernização do aparelho científico-tecnológico e, ainda, ao desenvolvimento econômico nacional e regional e à inserção competitiva do Estado e respectivo bloco regional na economia mundializada.

A educação, em geral, e a educação superior, em particular, vistas como elementos-chave da nova estratégia desenvolvimentista, tornam-se fator determinante para o potencial de soberania, inovação e competitividade de cada país e do bloco regional ao qual ele pertence, ao mesmo tempo em que se tornam elemento de coesão social, tendo em vista seu papel disciplinador, (con)formador na transmissão de valores e da ideologia dominante.

A aparência fenomênica mostra a criação de programas e instrumentos voltados para a formação de pessoal qualificado à pesquisa, a produção de conhecimento científico com vistas ao desenvolvimento do aparato científico e a manutenção de infraestrutura de pesquisa com financiamento do fundo público voltado ao desenvolvimento econômico. $\mathrm{Na}$ essência, encontram-se as formas históricas de subordinação do trabalho manual e do trabalho intelectual à lógica da acumulação capitalista, estando tal política relacionada ao poder burguês, à ideologia da modernização e do desenvolvimento econômico, ao mercado, à racionalidade instrumental e ao controle social (idem).

Assim sendo, a universidade de fins do século XX e início do XXI, em oposição aos modelos humboldtiano e napoleônicos, deve ser aquela que, articulada de modo subordinado às dinâmicas da política de ciência, tecnologia e inovação, organiza-se dinâmica e flexivelmente, de maneira que acompanhe a internacionalização da economia e da tecnologia, por mediação da reestruturação acadêmico-pedagógica rumo à internacionalização do conhecimento em nível regional e mundial. Além desse aspecto essencial, a universidade apresenta-se com uma feição "mais democrática" e "mais humanizadora", por conseguinte, de "interesse geral" - aberta às massas e, sobretudo, às demandas do empresariado -; portadora de espírito empresarial; não sendo mais una, comporta várias missões, que vão desde o ensino, pesquisa e produção de inovação aos serviços prestados à 
coletividade, passando pelo compromisso de promover a harmonia entre capital e trabalho. Não sendo una, em seu aspecto institucional, a universidade, tal como concebida no modelo anglo-saxão modernizado, reúne uma diversidade de instituições, contraditoriamente hierarquizadas segundo os ramos do saber, oferta e qualidade dos cursos, cuja missão volta-se para a formação de parte do trabalhador coletivo, em diferentes modalidades de cursos de tempos de duração acoplados aos tempos do mercado e aos desígnios do capital.

Por detrás dessa estratégia neoliberal manifesta-se o fenômeno de empresariamento da educação (Martins, 2007; Neves, 2002, 2005; Rodrigues, 1998, 2007), ou ainda, na expressão de Correia (2011, p. 172), da "pedagogização da empresa" e da "empresarialização da pedagogia", inserido no processo de liberalização e intensificação mundial do comércio, liderado pela Organização Mundial do Comércio (OMC) por meio do Acordo Geral sobre Comércio de Serviços (GATS), ${ }^{17}$ tendo como protagonistas discretos, mas centrais, importantes grupos de pressão empresariais que atuam mediatamente no poder político.

São frações burguesas consideradas de relevante influência no curso das transformações da política educativa, em níveis regional (no âmbito do MERCOSUL), nacional e internacional. Entre os grupos nacionais, embora com ramificações além-fronteira, destacam-se: Confederação Nacional da Indústria, Fundação Bradesco, Fundação Gerdau, Fundação Victor Civita, Instituto Ayrton Senna, Instituto Euvaldo Lodi, além de grandes conglomerados educacionais, capitaneados por grupos econômicos do porte das redes Anhanguera e Kroton, Estácio Participações S.A., e Grupo UNINTER, a maioria com aporte de capital estrangeiro e participação no mercado financeiro.

Concorda-se, pois, com Leher (2009), quando afirma que, embora acordos como o da Área de Livre Comércio das Américas (ALCA) e o GATS/OMC não tenham sido efetivados com a amplitude prevista, os processos de privatização, de comodificaçãa ${ }^{18}$ e mercantilização da educação continuam enérgicos na região sul-americana, particularmente no campo da educação superior.

De um lado, a fração burguesa da indústria atua de modo sistemático, por meio do argumento da hélice tripla, buscando, permanentemente, ampliar os canais institucionais que permitam às demandas do setor empresarial chegar à universidade. Com a finalidade de elevar a produtividade do trabalho, aumentar o lucro e estimular a inovação, "encaram a educação e o conhecimento como mercadoria-

17 O GATS foi estabelecido no ano de 1994, na conclusão dos debates do "Ciclo Uruguaio" do GATT (General Agreement on Tariffs and Trade - Acordo Geral sobre Tarifas e Comércio), que propiciou a criação da OMC. O GATS busca a liberalização do comércio de serviços, permitindo às empresas transnacionais apoderarem-se dos serviços públicos estatais. A educação superior é um dos doze ramos do acordo que prevê diversos serviços educacionais: fornecimento de educação além-fronteiras, consumo da educação no exterior, presença comercial e presença de pessoas do país fornecedor no país atendido.

18 Do inglês commodification, processo no qual os direitos sociais e subjetivos, a exemplo da educação, são transformados em mercadoria, de modo análogo ao que ocorre no mercado de bens e produtos (commodities). 
-educação" (Rodrigues, 2007), incentivando a formação de pessoal qualificado nas universidades públicas não apenas para as atividades de produção, mas também para o desenvolvimento científico-tecnológico. Requisitam, portanto, a ampliação do número de mestres e doutores predominantemente para as áreas de ciências exatas, em especial na das engenharias, bem como o direcionamento da produção acadêmica para a geração de patentes, de riquezas e de desenvolvimento regional e nacional, pré-requisito para se inserir na economia globalizada.

De outro lado, a fração burguesa dos serviços educacionais, reforçada pelo desmantelamento da educação pública e gratuita promovida principalmente pelos governos neoliberais de Collor de Mello (1990-1992) e Itamar Franco (1992-1995), passando por Fernando Henrique Cardoso (1995-2003) e Luiz Inácio Lula da Silva (2003-2011), até o mandato de Dilma Rousseff, encaram a "educação-mercadoria" (idem) como um negócio rentável, ofertando cursos voltados aos interesses imediatos do mercado.

Por sua vez, a Secretaria de Educação Superior (SESu/MEC), em articulação com a CONAES,${ }^{19}$ em consonância com o Setor Educacional do MERCOSUL (SEM), reconhece a qualidade acadêmica dos diplomas outorgados por instituições de ensino superior universitário, públicas e privadas, cujos cursos vêm recebendo o selo de padrão de qualidade com certificação ISO 9000 (Magalhães, 2007; Silveira, 2011), garantindo oficial e publicamente a validez das titulações acadêmicas e habilitações profissionais, em escala regional e mundial, segundo os interesses do mercado e do GATS. O excerto seguinte torna mais explícita essa questão.

También, hay que sopesar qué ventajas comparativas podrían obtener nuestros países, si es que hubiera alguna posibilidad de "exportar" servicios de enseñanza, sobre todo en este segmento, pero también en el modo 2 (consumo en el extranjero), a partir de la oferta atractiva de titulaciones de posgrado, sistemas de educación con calidad reconocida internacionalmente y carreras acreditadas. Todo ello tendencialmente incrementado con la puesta en marcha del Mecanismo de Acreditación MERCOSUR, que otorgará un "sello" de calidad extra a las carreras acreditadas. (MERCOSUL; CRCES; GATS, 2002)

\section{CONSIDERAÇÕES FINAIS}

Conclui-se a análise sobre a concepção de universidade retornando ao início deste texto, quando se aponta para as orientações dos Relatórios Robbins e Atcon, bem como para a condição pós-moderna de universidade explicitada por Lyotard e Readings. Ao que tudo indica, a universidade modernizada, construída historicamente desde os anos 1960, representa a vitória do capital, pelo menos no decurso dessa temporalidade em sua fase neoliberal. Eis que evidencia seu caráter contrarreformista

19 Para mais detalhes, ver: <http://portal.mec.gov.br/index.php?option=com_content\&vi ew=article\&id=15305\&Itemid=1075>. Acesso em: 16 jun. 2015. 
concretizado na privatização, mercantilização e comodificação da educação superior no Brasil.

O modelo de universidade sendo colocado em prática revela sua inspiração na agenda de organismos supranacionais coerente com políticas privatistas desenvolvidas pelo MEC, que designa a educação como bem público - um serviço passível de ser oferecido diretamente pelo Estado ou pela iniciativa privada; promove a integração subordinada da universidade aos imperativos da acumulação e reprodução do capital, transformando as IES em organizações prestadoras de serviços (ensino, pesquisa e extensão); vincula estreita e indissociavelmente o plano de desenvolvimento institucional ao setor produtivo; padroniza currículos e instrumentos de avaliação sob a ação do marco regulatório do Setor Educacional do MERCOSUL (SEM), por mediação do Estado, bem como a diversificada fonte de financiamento.

Outro aspecto essencial diz respeito à formação do trabalhador coletivo. A divisão internacional do trabalho que separa concepção e execução, trabalho intelectual e trabalho manual, transformando as formas de reprodução do capital e da força de trabalho, abre espaço para a expansão de diferentes ofertas formativas. Do ponto de vista do capital (há países e blocos nos quais predomina a concepção com maior valor agregado -, e em outros, a execução/montagem), a diferenciação e hierarquização de IES e a diversificação de cursos são partes de um sistema de ensino preparador de variadas capacidades de trabalho que cooperam e participam de maneira diversificada no processo imediato de criação e circulação de mercadorias, bens e serviços, constituindo a máquina produtiva total.

Ao longo de sua breve, mas intensa história, a universidade brasileira ainda não viveu um processo democrático de reforma, com origem em seus protagonistas, para afirmá-la como instituição pública, gratuita, autônoma, universal, locus de socialização e de produção de conhecimento novo (Leher, 2007).

Diante do que foi exposto, seria de esperar algo diferente quando a educação/ formação é sacrificada no altar do mercado?

\section{REFERÊNCIAS}

Amaral, A.; Magalhães, A. O conceito de stakeholder e o novo paradigma de ensino superior. Revista Portuguesa de Educação, Braga: UM, v. 13, n. 2, p. 7-28, 2000.

Anderson, P. Balanço do neoliberalismo. In: Sader, E.; Gentili, P. (Orgs.) Pós-neoliberalismo: as políticas sociais e o Estado democrático. Rio de Janeiro: Paz e Terra, 1995. p. 9-23.

Atcon, R. P. La universidad latinoamericana: clave para un enfoque conjunto del desarrollo coordinado social, económico y educativo en América Latina. Bogotá: Universidade Nacional de Colombia, 1961. Disponível em: <http://pt.scribd.com/ doc/36270991/Rudolph-Atcon-La-Universidad-a-v-libro>. Acesso em: 5 jan. 2011.

Barros, R. S. M. A ilustração brasileira e a ideia de universidade. São Paulo: Convívio; EDUSP, 1986.

Bianchetti, L. Pós-graduação em educação: processo e resultados de uma "indução voluntária”. Universidade e Sociedade, Brasília: ANDES, v. 41, p. 143-164, 2008. 
.; Quartiero, E. M. Researchers under pressure: a comparative study of new forms of producing, advising and transmitting knowledge in Brazil and the European Union. European Educational Research Journal, Oxford, UK: ECER, v. 9, p. 498-509, 2010.

Boaventura, E. M. Universidade e multiversidade. Rio de Janeiro: Tempo Brasileiro, 1986.

BRASIL; MEC; EAPES. Relatório da equipe de assessoria ao planejamento do ensino superior (Acordo MEC-USAID). Brasília: MEC; EAPES, 1969.

Cardoso, M. L. Ideologia do desenvolvimento - Brasil:JK-JQ. 2. ed. Rio de Janeiro: Paz e Terra, 1978.

Chesnais, F. A mundialização do capital. São Paulo: Xamã, 1996.

Ciavatta, M. Mediações históricas de trabalho e educação: gênese e disputa na formação dos trabalhadores (Rio de Janeiro, 1930-60). Rio de Janeiro: Lamparina; CNPq; FAPERJ, 2009.

Condorcet, J. A. N. C. Cinco memórias sobre a instrução pública. São Paulo: UNESP, 2008.

Correia, J. A. Construção político-cognitiva da exclusão social no campo educativo. In: Bianchetti, L.; Correia, J. A. In/exclusão no trabalho e na educą̧ão. Aspectos mitológicos, históricos e conceituais. Campinas: Papirus, 2011. p. 172.

Cunha, L. A. A universidade temporã: o ensino superior da Colônia à Era Vargas. Rio de Janeiro: Unesp, 1980.

Fávero, M. L. A. Da universidade "modernizada" à universidade disciplinada: Atcon e Meira Mattos. São Paulo: Cortez; Campinas: Autores Associados, 1991.

A educação no Congresso Constituinte de 1966-67: contrapontos. In:

(Org.). Educação nas constituintes brasileiras 1823-1988. 2. ed. Campinas: Autores Associados, 2001.

Fernandes, F. Educação e sociedade no Brasil. São Paulo: EDUSP, 1963.

Universidade brasileira: reforma ou revolução? São Paulo: Alfa-Ômega, 1975.

Universidade e desenvolvimento. In: Ianni, O. (Org.). Florestan Fernandes: sociologia crítica e militante. São Paulo: Expressão Popular, 2004. p. 273-316.

Fiori, J. L. O quebra-cabeça da esquerda europeia. In: FioRI, J. L. O poder global e a nova geopolitica das nações. São Paulo: Boitempo, 2007. p. 193-197.

FRigotTo, G. A produtividade da escola improdutiva: um (re)exame das relações entre educação e estrutura econômico-social e capitalista. 7. ed. São Paulo: Cortez, 2001.

Goergen, P. A universidade em tempos de transformação. Campinas: UNICAMP, s.d. Disponível em: <http://www.prg.unicamp.br/Texto_univ_em_temp_trans_Pedro_ Goergen.html >. Acesso em: 12 nov. 2009.

Gomes, A. C. (Coord.). Engenheiros e economistas: novas elites burocráticas. Rio de Janeiro: Editora FGV, 1994.

Gramsci, A. Cadernos do cárcere. II Risorgimento: notas sobre a história da Itália. 2. ed. Rio de Janeiro: Civilização Brasileira, 2002.v. 5.

Новsваwм, E. A era das revoluções: 1789-1848. 25. ed. São Paulo: Paz e Terra, 2012. 
Нumboldt, W. V. Sobre a organização interna e externa das instituições científicas superiores em Berlim. In: CASPER, G.; Humboldt, W. V. Um mundo sem universidades? 2. ed. Rio de Janeiro: EdUERJ, 2003. p. 15-34.

LEHER, R. Estrategias de mercantilización de la educación y tiempos desiguales de los tratados de libre comercio: el caso de Brasil. In: Gentili, P.; Frigotto, G.; Leher, R.; Stubrin, F. (Orgs.). Politicas de privatización, espacio público y educación en América Latina. Rosário: Homo Sapiens Ediciones, 2009. p. 15-65.

Lyotard, J.-F. A condição pós-moderna. 13. ed. Rio de Janeiro: José Olympio, 2011.

Magalhães, G. Selos de qualidade para cursos do Mercosul. Brasília: MEC; Notícias, 13 abr. 2007. Disponível em: <http://portal.mec.gov.br/index.php?option=com_ content\&task=view\&id=8009>. Acesso em: jul. 2011.

Martins, A. S. Burguesia e a nova sociabilidade: estratégias para educar o consenso no Brasil contemporâneo. 2007. Tese (Doutorado em Educação) - Universidade Federal Fluminense, Niterói, 2007.

MARx, K. Elementos fundamentales para la critica de la economia politica (Grundisse) 1857-1858. v. 2 e 3, 8. reimp. México: Siglo XXI Editores, 2009.

Mercosul. Setor Educacional do Mercosul. El acuerdo general de comercio de servicios y la educación. Vinculación con el Mercosur. In: Reunião da Comissão Regional Coordenadora de Educação Superior, 6., 2002, Montevideo. Atas... Montevideo: Mercosul; SEM; CRES, 2002.

Moore JR., B. As origens sociais da ditadura e da democracia: senhores e camponeses na construção do mundo moderno. Lisboa: Edições 70, 2010.

Neves, L. M.W. (Org.). O empresariamento da educação. São Paulo: Xamã, 2002.

. A sociedade civil como espaço estratégico de difusão da nova pedagogia da hegemonia. In: __. (Org.). A nova pedagogia da hegemonia: estratégias do capital para educar o consenso. São Paulo: Xamã, 2005.

Nunes, A. S. Para a reforma da universidade: um importante debate em França. Revista Análise Social, Lisboa: UL/ICS, v. IV, n. 16, p. 684-696, 1966.

Piozzı, P.Da necessidade à liberdade: uma nota sobre as propostas de Diderot e Condorcet para o ensino superior. Educação E̊ Sociedade, Campinas: CEDES, v. 25, n. 88, p. 655-676, out. 2004.

Ralha, A. As universidades portuguesas em face dos diferentes tipos de universidade. Revista Análise Social, Lisboa: UL/ICS, v. VI, n. 20-21, p. 99-126, 1968.

Readings, B. Universidade sem cultura? 2. ed. Rio de Janeiro: EdUERJ, 2002. A universidade em ruinas. Coimbra: Angelus Novus, 2003.

Robisns, L. Robbins Report (1963). Londres: Her Majesty's Stationery Office, 1963. Disponível em: $<$ http://www.educationengland.org.uk/documents/robbins/robbins00. html $>$. Acesso em: jul. 2010.

Rodrigues, J. O moderno principe industrial: o pensamento pedagógico empresarial da Confederação Nacional da Indústria. Campinas: Autores Associados, 1998. . Os empresários e a educą̧ão superior. Campinas: Autores Associados, 2007. 
RodRIGUÉz, R. V. Napoleão Bonaparte: imperador dos franceses - duzentos anos, 1804-2004. Portal da Defesa, Juiz de Fora: UFJF, 2004. p. 1-49. Disponível em: <http://www. ecsbdefesa.com.br/defesa/fts/Napole\%E3o.pdf >. Acesso em: nov. 2009.

Silveira, Z. S. Contradições entre capital e trabalbo: concepções de educação tecnológica na reforma do ensino médio e técnico. Jundiaí: Paco Editorial, 2010.

. Concepşões de educação tecnológica na reforma da educação superior: finalidades, continuidades e rupturas - estudo comparado Brasil e Portugal (1995-2010). 2011. 445f. Tese (Doutorado em Educação) - Faculdade de Educação, Universidade Federal Fluminense, Niterói.

Teixeira, A. A universidade de ontem e de hoje. Revista Brasileira de Estudos Pedagógicos, Rio de Janeiro: INEP; CBPE, v. 42, n. 95, p. 27-47, jul./set. 1964.

. Uma perspectiva da educação superior no Brasil. Revista Brasileira de Estudos Pedagógicos, Rio de Janeiro: INEP; CBPE, v. 50, n. 11, p. 21-82, jul./set. 1968.

\section{SOBRE OS AUTORES}

Zuleide Simas de Silveira é doutora em educação pela Universidade Federal Fluminense (UFF). Professora da mesma instituição.

E-mail: zuleidesilveira@terra.com.br

Lucídio Bianchetti é doutor em educação pela Pontifícia Universidade Católica de São Paulo (PUC-SP). Professor associado da Universidade Federal de Santa Catarina (UFSC).

E-mail: lucidiob@uol.com.br

Recebido em novembro de 2013 Aprovado em julbo de 2014 